\title{
RECICLAGEM E GESTÃO DE RESÍDUOS SÓLIDOS COMO POSSIBILIDADES PARA AERAÇÃO DE BENEFÍCIOS SOCIAIS, ECONÔMICOS E AMBIENTAIS*
}

\author{
Osmar Tomaz de Souza** \\ Iara Regina Chaves*** \\ Augusto Mussi Alvim*****
}

\begin{abstract}
Resumo
No presente artigo são apresentadas algumas reflexões relacionadas à produção e gestão dos resíduos sólidos no Brasil. Em particular, discute-se o potencial de geração de benefícios sociais, econômicos e ambientais da gestão de resíduos no país a partir das definições da Política Nacional de Resíduos Sólidos, criada por lei no ano de 2010. Esta define objetivos e metas para a gestão de resíduos no país. Dentre estes, destaca-se que até o ano de 2014 todos os municípios deveriam contar com a gestão ambientalmente correta dos resíduos, o que não foi cumprido, visto que o cenário recente mostra que em torno de 50\% dos resíduos sólidos produzidos são destinados aos vazadouros a céu aberto, os "lixões". Isso representa não somente um desperdício do ponto de vista econômico, como também do ponto de vista social e ambiental, dado o potencial que eles apresentam para o reuso e o reaproveitamento.
\end{abstract}

Palavras-chave: Reciclagem. Política Nacional de Resíduos Sólidos. Benefícios socioeconômicos e ambientais.

\footnotetext{
* Resultados da pesquisa "Benefícios Econômicos, Sociais e Ambientais da Reciclagem de Resíduos Sólidos Urbanos nos Municípios Brasileiros no Período 2007-2010", apoiada pela Fundação de Amparo à Pesquisa do Rio Grande do Sul - Fapergs, Edital PQG 04/2012.

** Doutor em Desenvolvimento e Meio Ambiente pela Universidade Federal do Paraná (2006). Pós-doutor pela Université Paris Ouest Nanterre - La Defense (França) (2013-2014). Professor Pesquisador do Programa de PósGraduação em Economia da Pontifícia Universidade Católica do Rio Grande do Sul - PPGE/PUCRS. E-mail: osmar.souza@pucrs.br

*** Doutoranda em Qualidade Ambiental na Feevale - RS. E-mail: iara.chaves@ig.com.br

**** Doutor em Economia (2003) pela Universidade Federal do Rio Grande do Sul. Pós-doutor na Massey University na Nova Zelândia (2007). Professor Visitante na Universidade de Newcastle na Inglaterra (2012). Consultor do Instituto Interamericano de Cooperacion para la Agricultura, IICA (2009). Professor Titular na Faculdade de Administração, Contabilidade e Economia da Pontifícia Universidade Católica e Coordenador do Programa de Pós-Graduação em Economia da PUCRS. E-mail: augusto.alvim@pucrs.br.
} 


\section{Introdução}

A sustentabilidade do desenvolvimento ganhou relevância nas últimas décadas especialmente por conta do aprofundamento da relação entre sociedade e meio ambiente no que se refere aos impactos produzidos pelo modelo produtivo e pelo padrão de consumo predominante. Embora a "sustentabilidade" e o "desenvolvimento sustentável" não sejam ainda conceitos de consenso, algumas de suas características são mais amplamente aceitas. Por exemplo, a ideia de que envolvem múltiplas dimensões das relações entre sociedade e natureza e também uma vasta gama de requisitos para que possa aceitar um desenvolvimento somo sendo "sustentável".

A interdependência entre bem-estar e qualidade ambiental, saneamento e saúde da população são exemplos do olhar mais atento para o papel dessas interações na qualidade de vida da população ou na sustentabilidade do desenvolvimento. Em um modelo de desenvolvimento em que a produção de resíduos vem apresentando crescimento contínuo em decorrência do aumento da renda e do padrão de consumo vigente, os problemas relacionados ao mau gerenciamento desses resíduos colocam-se tanto como um problema ambiental, quanto social e econômico. Ou seja, além da degradação do ambiente natural, piora as condições de vida das populações, diminuindo seu bem-estar, o que representa um desperdício do ponto de vista do seu aproveitamento econômico e do seu potencial de geração de emprego e renda.

Com o crescimento das cidades e o aumento da quantidade de resíduos produzido pela população, os problemas relacionados à má gestão de resíduos ganharam novas proporções. Considerada um dos setores do saneamento básico, a gestão dos resíduos sólidos não vinha merecendo a atenção necessária por parte do poder público até recentemente. A Lei 12.305/2010, de 8 de agosto, define a Política Nacional de Resíduos Sólidos e reúne o conjunto de princípios, objetivos, instrumentos, diretrizes, metas e ações com vistas à gestão integrada e ao gerenciamento ambiental adequados dos resíduos sólidos.

Os resíduos passam a ser vistos sob outra perspectiva. O que antes era chamado de lixo passa a ser identificado como resíduos e materiais recicláveis, capazes de devolver à sociedade valor econômico, sustentabilidade ambiental e até mesmo dignidade às pessoas que fazem deles um meio de geração de trabalho e renda. Motta e Chermant (1996) lembram que a reciclagem, enquanto 
objeto de incentivo por políticas governamentais, só será viável economicamente e desejável socialmente se suas vantagens forem comprovadas em termos de eficiência econômica e ambiental. De qualquer forma, sabe-se que independentemente dos benefícios econômicos da reciclagem, a boa gestão dos resíduos sólidos, em sentido mais amplo, pode apresentar resultados favoráveis nos aspectos socioambientais.

O objetivo do presente trabalho é apresentar um panorama do atual cenário da gestão de resíduos sólidos no Brasil e, em especial, refletir sobre as possibilidades de benefícios sociais, econômicos e ambientais associados à reciclagem. Para isso, este artigo está estruturado em seis partes, incluindo esta introdução. No item 2 são apresentados alguns pontos do atual debate sobre a questão dos resíduos sólidos e as definições da política nacional que abordam o assunto. $\mathrm{O}$ item 3 dá enfoque ao cenário da produção e gestão dos resíduos sólidos no Brasil. Já no item 4, destacam-se os benefícios socioeconômicos e ambientais que a reciclagem pode oferecer à sociedade. Por último, são apresentadas as considerações finais.

\section{A questão dos resíduos e a política nacional dos resíduos sólidos}

Recentemente, as questões relacionadas ao saneamento básico e às formas de gestão dos resíduos passaram a ocupar mais espaço nos debates concernentes ao "desenvolvimento sustentável" devido ao entendimento de que estes são fundamentais à garantia da qualidade de vida e ao bem-estar da população.

A preocupação mundial em relação aos resíduos sólidos tem aumentado devido ao aumento da produção, ao aumento da periculosidade de alguns resíduos, ao gerenciamento inadequado e à falta de área para disposição final desses resíduos.

$\mathrm{Na}$ CNUMAD, mais de 180 países, incluindo cerca de 100 chefes de estado, formalizaram cinco documentos direta ou indiretamente relacionados com a proteção e conservação da biodiversidade em nível global, a saber: Convenção sobre Biodiversidade; Convenção sobre Mudanças de Clima; Agenda 21; Princípios para Administração Sustentável das Florestas; Declaração do Rio sobre Meio Ambiente e Desenvolvimento.

A Agenda 21 é um instrumento estratégico de gerenciamento compatível com a preservação do meio ambiente que busca a 
minimização na produção de resíduos, a maximização de práticas de reutilização e reciclagem ambientalmente corretas, a promoção de sistemas de tratamento e disposição dos resíduos compatíveis com a preservação ambiental e a ampliação do alcance dos serviços que se ocupam dos resíduos. Estando essas áreas relacionadas, estas devem estar integradas a fim de constituir uma estrutura ampla e ambientalmente saudável para o manejo dos resíduos sólidos urbanos (CRESPO, 2003).

Ela representaria um processo de planejamento participativo que analisa a situação atual de um país, estados, município e/ou região e planeja o futuro de forma sustentável. Esse processo de planejamento deve envolver todos os atores sociais na discussão dos principais problemas e na formação de parcerias e compromissos para a sua solução a curto, médio e longo prazo.

Para a United Nations Conference on Environment and Development (UNCED 1992) ou (CNUMAD) a Agenda 21 destacou os capítulos 4, 20, 21, 22 e 30 para desenvolver cenários elementares na geração, no sistema de gerenciamento e na disposição final de resíduos. Destaca-se, no capítulo 21, intitulado "Manejo ambientalmente saudável dos resíduos sólidos e questões relacionadas com os esgotos", que:

O manejo ambiental saudável dos resíduos deve ir além da simples deposição final ou seu aproveitamento por métodos seguros dos resíduos gerados e buscar resolver a causa fundamental do problema, procurando mudar os padrões não sustentáveis de produção e consumo. Isto implica na utilização do conceito de manejo integrado do ciclo de vida do produto (Integrated Life Cycle Management), um instrumento que apresenta a oportunidade única de conciliar o desenvolvimento com a proteção ao meio ambiente. (BRASIL, 2009a).

Esse gerenciamento baseia-se na análise, avaliação ou apreciação do ciclo de vida do produto (Life Cycle Assessment), que significa procurar conhecer todos os impactos do produto sobre o meio ambiente, desde a extração das materiais-primas, seu transporte e beneficiamento, passando pelos processos de produção, comercialização, uso, manutenção, descarte e disposição final.

Ainda segundo a Agenda 21, a estrutura da ação necessária deve apoiar-se em uma hierarquia de objetivos a centrar-se nas quatro principais áreas de programas relacionadas com resíduos, 
a saber: redução ao mínimo de resíduos; aumento ao máximo da reutilização e reciclagem ambiental saudáveis dos resíduos; promoção do tratamento e da disposição ambiental saudáveis dos resíduos; e ampliação do alcance dos serviços que se ocupam dos resíduos.

Portanto, na formulação de políticas públicas que visam o gerenciamento ambiental adequado dos resíduos, devem ser utilizados instrumentos econômicos, tecnológicos e científicos, tendo como objetivo: a redução da geração de resíduos; a reutilização; a reciclagem; o tratamento e o destino final ambientalmente saudáveis; e a ampliação do alcance dos serviços (universalização). Os objetivos têm como base os princípios dos 3Rs, amplamente difundidos como o caminho apontado para a solução dos problemas relacionados com o lixo - Reduzir, Reutilizar e Reciclar.

A Associação Brasileira de Normas Técnicas - ABNT define o lixo como os "restos das atividades humanas, considerados pelos geradores como inúteis, indesejáveis ou descartáveis, podendo-se apresentar no estado sólido, semissólido 1 ou líquido 2, desde que não seja passível de tratamento convencional."

O termo "resíduo sólido", por seu lado, é mais comumente usado na linguagem acadêmica ou no meio técnico, sendo o termo "lixo" mais empregado na linguagem coloquial. A Associação Brasileira de Normas Técnicas (ABNT), por meio da norma NBR no 10.004:2004, e o conselho Nacional de Meio Ambiente (Conama), com a Resolução no 005/1993, definem resíduos sólidos como:

Resíduos nos estados sólido e semissólido que resultam de atividades de origem industrial, doméstica, hospitalar, comercial, agrícola e de serviços de varrição. Ficam incluídas nesta definição os lodos provenientes de sistemas de tratamento de agua, daqueles gerados em equipamentos e instalações de controle de poluição bem como determinados líquidos cujas particularidades tornem inviável o seu lançamento na rede pública de esgotos ou corpos de agua, ou exijam para isso soluções técnicas e economicamente inviáveis em face a melhor tecnologia possível (CONAMA, 1993, p.1).

No Brasil, a Política Nacional de Resíduos Sólidos foi instituída pela Lei no 12.305, de 2 de agosto de 2010 e representa um avanço fundamental para a regulação do setor no país. Ela 
reúne o conjunto de princípios, objetivos, instrumentos, diretrizes, metas e ações com vistas à gestão integrada e ao gerenciamento ambiental adequados dos resíduos sólidos. Além disso, determina que é de responsabilidade dos municípios a gestão integrada dos resíduos sólidos gerados nos respectivos territórios.

Essa lei ainda define que a União deverá elaborar, sob a coordenação do Ministério do Meio Ambiente, o Plano Nacional de Resíduos Sólidos (PNRS), a ser atualizado a cada quatro anos. Os estados e municípios também deverão elaborar os respectivos Planos Estaduais e Municipais de Resíduos Sólidos, como condição para terem acesso a recursos da União destinados a empreendimentos e serviços relacionados à gestão de resíduos sólidos (no caso dos estados) ou destinados a empreendimentos e serviços relacionados à limpeza urbana e ao manejo de resíduos sólidos (no caso dos municípios).

A Lei estabeleceu prazos ou limites temporais para algumas ações, tais como a eliminação de lixões e a consequente disposição final ambientalmente adequada dos rejeitos até 2014. Nesses casos, não se trata do estabelecimento de um Plano de Metas, mas sim do cumprimento de prazos legais. As demais ações em que a Lei 12.305/2010 não estabeleceu prazos máximos para o seu cumprimento foram objeto de Planos de Metas alternativos (Plano de Metas “Intermediário”e Plano de Metas “Desfavorável”), permitindo que durante as audiências e a consulta pública seja possível construir o Plano de Metas mais adequado para cada situação apresentada.

\section{Cenário dos resíduos sólidos no Brasil}

O Brasil gerou mais de 57 milhões toneladas de resíduos sólidos em 2009, um crescimento de 7,7\% em relação ao volume do ano anterior. As capitais e as cidades com mais de $500 \mathrm{mil}$ habitantes foram responsáveis por quase 23 milhões de toneladas de RSU dia (ABRELPE, 2009). Apesar desse rápido crescimento, vem verificando-se uma melhoria de alguns indicadores. Por exemplo, o atendimento da população pelos serviços de coleta de resíduos domiciliares na zona urbana está próximo da universalização. Observou-se uma expansão de 79\%, no ano 2000, para 97,8\% em 2008 nessa coleta (IBGE, 2010).

A média de geração de resíduos sólidos urbanos no país, segundo projeções da Abrelpe (2009), varia de 1 a 1,15 kg por 
hab./dia, padrão próximo aos dos países da União Europeia, cuja média é de $1,2 \mathrm{~kg}$ por dia por habitante. Para a Abrelpe, enquanto o crescimento populacional foi de apenas $1 \%$ entre os anos de 2008 e 2009, a geração per capita apresentou um aumento real de $6,6 \%$ na quantidade de resíduos domiciliares gerados (ABRELPE, 2009).

Esse é um crescimento que impõe desafios à prestação dos serviços de manejo de resíduos urbanos Os serviços de manejo dos resíduos sólidos compreendem à coleta, à limpeza pública, bem como à destinação final desses resíduos. $\mathrm{O}$ manejo dos resíduos sólidos exerce um forte impacto no orçamento das administrações municipais, podendo atingir 20,0\% dos gastos da municipalidade.

Talvez o problema mais crítico em relação ao manejo dos resíduos urbanos esteja na sua destinação, conforme apontam dados do Sistema Nacional de Informação sobre Saneamento (BRASIL, 2010). Na região Norte, ressalta-se que nos municípios do estado do Pará a destinação dos resíduos aos lixões foi praticada em 94,4\%. Na região Nordeste, os destaques negativos couberam aos municípios dos estados do Piauí, Maranhão e Alagoas com $97,8 \%, 96,3 \%$ e $96,1 \%$, respectivamente.

$\mathrm{Na}$ região Sul, o cenário mostrou-se mais positivo. Os municípios dos três estados - Santa Catarina, Rio Grande do Sul e Paraná - registraram as menores proporções de destinação dos resíduos sólidos aos lixões: 2,7\%,16,5\% e 24,6\%, respectivamente. $\mathrm{O}$ destaque coube aos municípios do estado de Santa Catarina, com $87,2 \%$ desses resíduos destinados a aterros sanitários e controlados.

Na região Sudeste, os municípios do estado de São Paulo registraram as menores proporções de destinação dos resíduos sólidos aos lixões, 7,6\%, enquanto os municípios do estado do Rio de Janeiro foram o destaque negativo, sendo esse tipo de destinação praticado em $33,0 \%$.

A matéria orgânica gerada nas residências representa mais de $50 \%$ da massa do lixo coletado e disposto em aterros sanitários e apenas 3\% são aproveitados em processos de compostagem (CEMPRE, 2010). Proveniente, em geral, do desperdício de alimentos, a matéria orgânica, quando disposta em aterros sanitários, ao se decompor, emite gases de efeito estufa e contribui para o aquecimento global e para as mudanças climáticas.

A disposição final dos resíduos sólidos urbanos em aterros sanitários tem aumentado ao longo dos últimos anos 
no país, segundo IBGE (2010). Enquanto no ano 2000 17,3\% dos municípios brasileiros utilizavam aterros sanitários para a destinação final, em 2008, passaram para 27,7\%. No entanto, cerca da metade dos municípios brasileiros ainda dispõem o lixo em lixões, e o percentual de cidades que dispõem em aterros controlados permaneceu praticamente estagnado nos oito anos, $22,3 \%$ (2000) e 22,5\% (2008). A crescente redução da disposição em lixões, verificada entre os anos 2000 e 2008, deve-se ao fato de as 13 maiores cidades, com população acima de um milhão de habitantes, coletarem mais de $35 \%$ de todo o lixo urbano do país e terem seus locais de disposição final adequada.

A Tabela 1, abaixo, mostra a situação da destinação final dos resíduos sólidos em anos selecionados. Observa-se que os vazadouros a céu aberto, conhecidos como "lixões", ainda são o destino final dos resíduos sólidos em 50,8\% dos municípios brasileiros, apesar de a situação ter evoluído desde 1989, quando o percentual era de $88,20 \%$. Os aterros sanitários evoluíram de 1,1\% para $27,7 \%$ e aterros controlados de $9,6 \%$ para $22,5 \%$ no mesmo período.

Tabela 1 - Destino final dos resíduos sólidos por unidades de destino dos resíduos (\%)

$$
\text { Brasil - 1989/2008 }
$$

\begin{tabular}{|c|c|c|c|}
\hline \multirow{2}{*}{ Ano } & \multicolumn{3}{|c|}{$\begin{array}{l}\text { Destino final dos resíduos sólidos por unidade de destino dos } \\
\text { resíduos \% }\end{array}$} \\
\hline & $\begin{array}{c}\text { Vazadouro a céu } \\
\text { aberto }\end{array}$ & Aterro controlado & Aterro sanitário \\
\hline 1989 & 88,20 & 9,60 & 1,10 \\
\hline 2000 & 72,30 & 22,30 & 17,30 \\
\hline 2008 & 50,80 & 22,50 & 27,70 \\
\hline
\end{tabular}

Fonte: IBGE (2008)

A PNSB-2008 (IBGE, 2010, p. 153) constatou que apenas dois dos 5.564 municípios brasileiros não possuem nenhum serviço de manejo de resíduos sólidos, enquanto que 99,6\% dos municípios possuem coleta regular de lixo. Ainda assim, vale ressaltar que cerca de 45,5\% dos municípios que contam com área de difícil acesso declararam realizar coleta parcial ou até mesmo não realizar coleta nessas áreas.

No que se refere à coleta seletiva, as primeiras informações oficiais foram levantadas pela PNSB em 1989, mostradas na 
Tabela 2. Naquele ano, apontava-se a existência de 58 programas de coleta seletiva no País. Esse número cresceu para 451 em 2000 e para 994, de acordo com a PNSB de 2008. Apesar da evolução, cabe destacar que esse número não representa nem $1 / 5$ do total de municípios brasileiros, o que indica um importante desperdício do potencial de aproveitamento dos resíduos pela reciclagem.

Tabela 2 - Evolução do número de programas de coleta seletiva no país

\begin{tabular}{cc}
\hline PNSB & Número de programas de coleta seletiva \\
\hline 1989 & 58 \\
2000 & 451 \\
2008 & 994 \\
\hline
\end{tabular}

Fonte: IBGE (2010)

Conforme o IBGE (2010) os primeiros programas de coleta seletiva e reciclagem dos resíduos sólidos no Brasil começaram a partir de meados da década de 1980, como alternativas inovadoras para a redução da geração dos resíduos sólidos domésticos e estímulo à reciclagem.

Desde então, comunidades organizadas, indústrias, empresas e governos locais têm sido mobilizados e induzidos à separação e classificação dos resíduos nas suas fontes produtoras. Tais iniciativas representaram um grande avanço no que diz respeito aos resíduos sólidos e à sua produção.

Conforme a última pesquisa, tal avanço ocorreu, sobretudo, nas regiões Sul e Sudeste, onde 46,0\% e 32,4\% dos municípios, respectivamente, informaram possuir programas de coleta seletiva que cobriam todo o município. $\mathrm{Na}$ região Sul, dos programas implementados, $42,1 \%$ concentravam-se em toda a área urbana da sede do município e 46,0\% cobriam todo o município. $\mathrm{Na}$ região Sudeste, $41,9 \%$ cobria toda a área urbana da sede municipal.

$\mathrm{Na}$ Figura 1 é apresentada a distribuição por região dos municípios com coletiva seletiva. Observa-se que 50\% dos municípios com coleta seletiva estão na região Sudeste, 36\% na região Sul, $10 \%$ na região Nordeste, 3\% no Centro-oeste e $1 \%$ na região Norte, ficando as regiões Sul e Sudeste com aproximadamente $86 \%$ do total dos municípios com coleta seletiva. Segundo Ciclosoft (2010), cerca de 22 milhões de brasileiros têm acesso a programas municipais de coleta seletiva e, 
apesar do número de cidades com esse serviço ter aumentado, na maior parte delas a coleta não cobre mais que $10 \%$ da população local.

Figura 1 - Municípios com coleta seletiva por região no Brasil

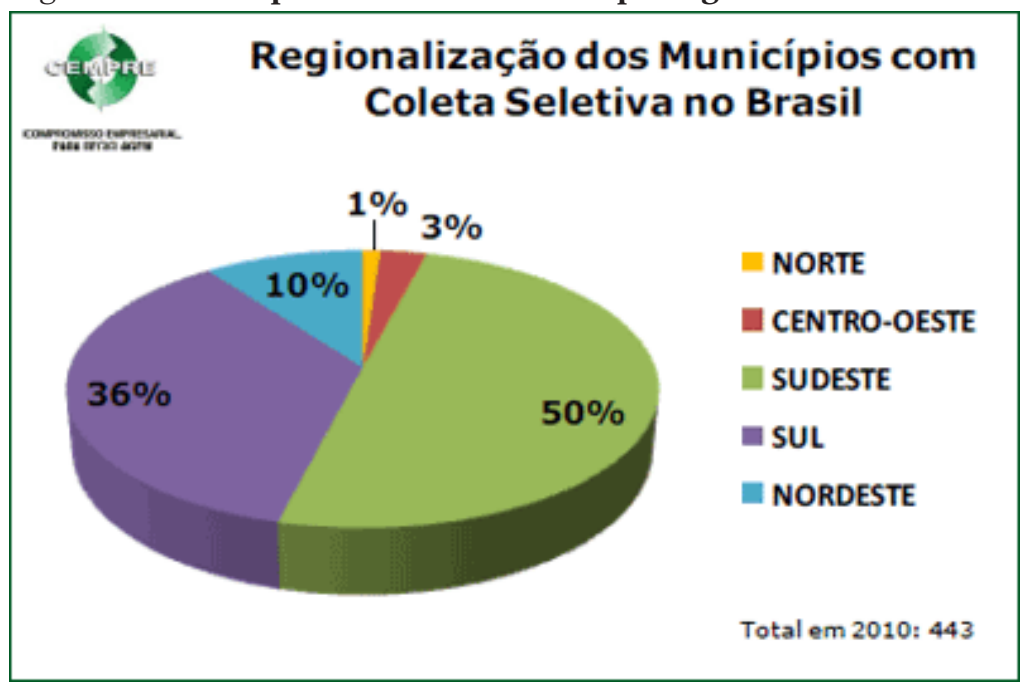

Fonte: CEMPRE (2010)

Um dos aspectos mais importantes da coleta seletiva é a composição gravimétrica dos resíduos, o que é apresentado na Figura 2, abaixo. Esta apresenta o percentual de cada componente em relação ao peso total do lixo. Essa composição é importante por indicar a possibilidade de aproveitamento das frações recicláveis para comercialização e da matéria orgânica para a produção de orgânico. No caso dos resíduos de origem domiciliar e comercial, normalmente dispostos em aterros, os componentes comumente discriminados na composição gravimétrica são: matéria orgânica putrescível, metais ferrosos, metais não ferrosos, papel, papelão, plásticos, trapos, vidro, borracha, couro, madeira, entre outros.

Os dados indicam que na coleta seletiva por material recolhido no Brasil, o item mais expressivo corresponde ao papel e ao papelão, com 39,9\% do total. Destacam-se, ainda, plásticos, que representam 19,5\%, vidros, com 11,9\% e metais, com 6,8\% do total. Em relação ao alumínio, é válido lembrar que embora o seu percentual seja pequeno, o seu percentual de reaproveitamento no Brasil supera os $90 \%$, especialmente graças ao trabalho realizado por catadores antes da sua disposição para a coleta formal dos sistemas municipais. 
A quantidade coletada de papel e/ou papelão, plástico, vidro e metal (materiais ferrosos e não ferrosos) têm como principais compradores os comerciantes de recicláveis $(53,9 \%)$, as indústrias recicladoras $(19,4 \%)$, entidades beneficentes $(12,1 \%)$ e outras entidades (18,3\%) (IBGE, 2008).

Cempre (2010) aponta que a porcentagem de rejeito ainda é grande, o que reforça a ideia de que é preciso tanto melhorar o serviço de coleta como conscientizar a população para separar o lixo corretamente em suas casas.

Figura 2 - Média da Composição Gravimétrica da Coleta Seletiva Brasil

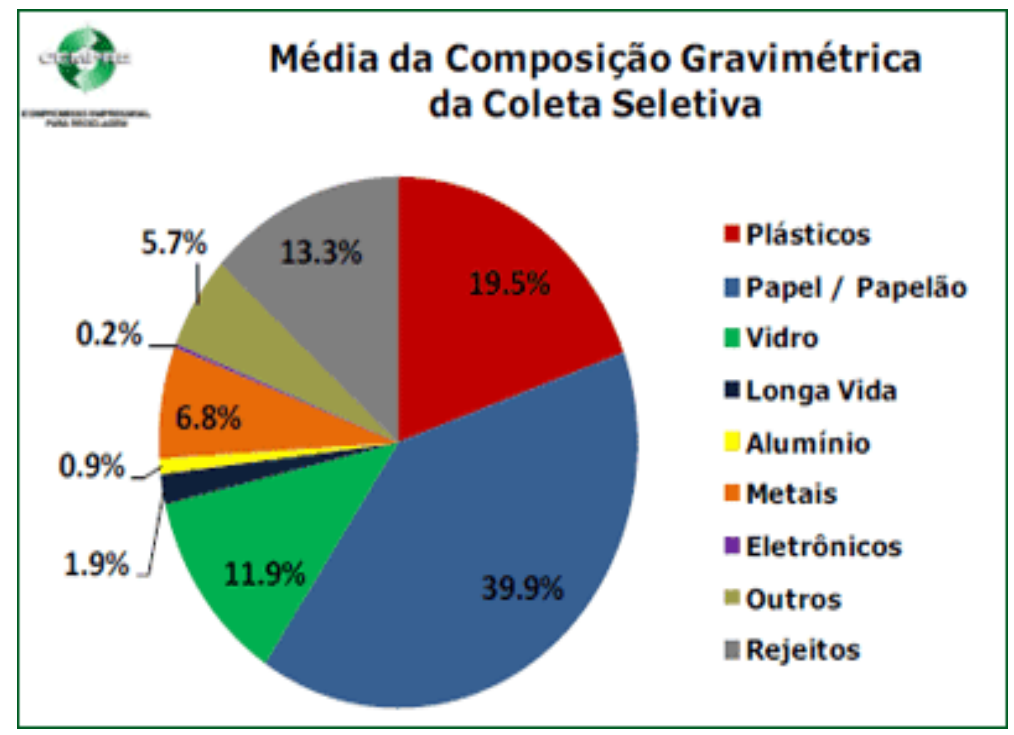

Fonte: Cempre (2010)

No Gráfico 1 é apresentada a evolução da média de custos da coleta seletiva entre 1994 e 2010. Ele varia de um máximo de US\$2 240 no primeiro ano da série até um mínimo de US\$ 70,00 no ano de 2002 . No ano de 2010 , observa-se que o custo médio da coleta seletiva nas grandes cidades foi de US\$204,00, o que equivale a $\mathrm{R} \$ 469,20$ em valores do mês de março/2014 (calculados ao câmbio de US\$1,00 = R $\$ 2,30$ ). Já o valor médio da coleta regular de lixo no mesmo ano foi de US\$ 47,22 (ou R\$ 108,60). Ou seja, o custo da coleta seletiva é quatro vezes maior que o custo da coleta convencional o que, a priori, pode representar um desincentivo à adoção da coleta seletiva. Contudo, existem vários outros aspectos a considerar no que tange aos benefícios da 
gestão adequada dos resíduos, conforme será discutido adiante. De qualquer forma, cabe lembrar que a diferença de critérios na divulgação dos custos dificulta a comparação entre os municípios, conforme destaca Ciclosoft (2010).

Gráfico 1 - Evolução Média de Custos de Coleta Seletiva (US\$/Ton.)

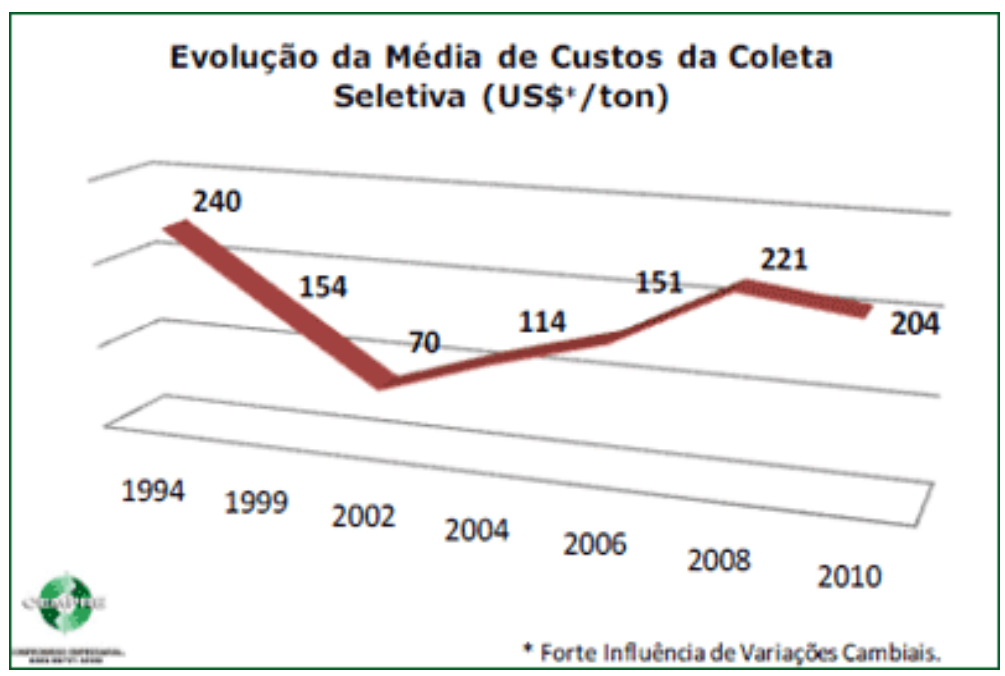

Fonte: Cempre (2010)

A Tabela 3 apresenta o percentual de resíduos sólido que o Brasil vem reciclando em comparação com alguns países selecionados. A Suécia apresentava um percentual de reciclagem de $40 \%$ do total dos seus resíduos em 2005. Os Estados Unidos, a Espanha e a França apareciam com 25\%. Já o Brasil apresentava apenas 11\% de reciclagem (CEMPRE, 2005).

Tabela 3 - Brasil no Cenário Mundial de Reciclagem de Resíduos Sólidos (\%) (Continua)

\begin{tabular}{lc}
\hline Pais & $\%$ \\
\hline Suécia & 40 \\
EUA & 25 \\
Espanha & 25 \\
França & 25 \\
Reino Unido & 15
\end{tabular}


Tabela 3 - Brasil no Cenário Mundial de Reciclagem de Resíduos

Sólidos (\%) (Continuação)

\begin{tabular}{lc}
\hline País & $\%$ \\
\hline Brasil & 11 \\
Tailândia & 10 \\
Grécia & 10 \\
Portugal & 5 \\
Polônia & 4 \\
México & 5 \\
Argentina & 3 \\
\hline
\end{tabular}

Fonte: Cempre (2005)

Este é um tipo de dado que ilustra o potencial do país em relação ao reaproveitamento dos resíduos e à diminuição dos problemas decorrentes da má gestão de resíduos. A destinação racional dos resíduos, sejam eles urbanos ou industriais, justifica-se, primeiramente, pela necessidade de evitar a sua simples deposição e contaminação do ambiente e, além disso, pela possibilidade de auferir renda a partir da reutilização. Ou seja, além das vantagens na questão ambiental, existem, ainda, os benefícios sociais e econômicos, uma vez que existem ganhos em relação à saúde e qualidade de vida da população e a possibilidade de geração de renda por meio da alocação do trabalho nos processos de coleta, triagem e processamento de resíduos.

\section{Notas sobre os benefícios socioeconômicos e ambientais da reciclagem}

O reaproveitamento dos resíduos sólidos contribui sobremaneira para a inclusão social de trabalhadores com baixo grau de instrução ou mesmo marginalizados do sistema formal de emprego, conforme apontam Barthlomeu et al. (2011). A renda auferida com a comercialização dos resíduos reutilizáveis geralmente retorna para os próprios trabalhadores e suas instituições. Também ocorre com certa frequência a concessão de benefícios aos trabalhadores por parte das prefeituras, tais como cestas básicas, auxílio-moradia, transporte ou mesmo alguma transferência de renda (bolsa). Essa é a lógica dominante de 
funcionamento das usinas de triagem de lixo no Brasil, segundo os autores. Com relação ao aspecto da geração de renda para a mão de obra de baixa qualificação, Strauch e Albuquerque (2008) lembram que não se deve olhar a produção e a reciclagem de resíduos como formas para a redução da pobreza. Ela deve ser entendida simplesmente como uma possibilidade a mais no rol de benefícios que uma gestão adequada de resíduos traz ao conjunto da sociedade.

Como lembra Calderoni (2003), a reciclagem de resíduos sólidos possui relevância ambiental, econômica e social por possuir ligações com diversas esferas como: organização espacial, preservação e uso racional dos recursos naturais, conservação e economia de energia, geração de empregos, desenvolvimento de produtos, finanças públicas, saneamento básico e proteção da saúde pública, geração de renda e redução de desperdícios na fonte. Motta (2006) menciona que o reaproveitamento de matérias advindas da reciclagem evita custos intratemporais relacionados com a poluição gerada pela disposição do lixo e custos envolvendo a utilização dos recursos exauríveis.

Nessa mesma linha, Calderoni (2003) lembra que os custos evitados podem englobar diferentes benefícios gerados pela reciclagem dos resíduos sólidos. $\mathrm{O}$ uso de certas matérias-primas pode ser reduzido com a reciclagem, não somente para os recursos exauríveis, como também para os recursos renováveis. Um exemplo é a utilização da celulose para a produção do papel que, mesmo com um manejo racional, acaba demandando extensas áreas para o plantio e remanejamento, além da poluição gerada no processo produtivo do papel.

Em relação aos aspectos econômicos, é preciso evitar as análises baseadas puramente em custos. Sabe-se que a reciclagem gera benefícios ambientais, sociais e econômicos, mas para a sua implementação e manutenção, os custos são mais elevados em relação à coleta normal. Ou seja, olhando simplesmente os custos de ambos os processos, seria possível presumir que a reciclagem é inviável. De acordo com Motta (2006) existiria uma falha de mercado para o município ou agente privado em razão do custo da reciclagem ser mais elevado do que o da coleta normal. Daí a necessidade atenção para os demais benefícios dessa prática.

Calderoni (2003) reforça que os custos da reciclagem podem ser mais elevados se analisados somente sobre a ótica de um agente e sem contar os benefícios gerados pela reciclagem em 
todo seu processo. Para os municípios, essa comparação direta (custo da coleta normal com relação à coleta seletiva), sem contar os benefícios adicionais que podem ser gerados, praticamente inviabilizaria a aplicação da coleta seletiva.

$\mathrm{Na}$ mesma linha, Strauch (2008) aponta que os custos para a coleta seletiva são mais elevados porque o investimento inicial é maior. A coleta seletiva necessita de gastos com logística, pessoal, combustível, caminhões e recipientes de coleta, porém reduz a intensidade no processo de triagem dos resíduos e resulta em uma qualidade superior da matéria reciclada para a venda.

Motta e Chermont (2006) ressaltam que o nível de reciclagem é determinado pela participação da matéria reciclável em relação ao total da matéria virgem utilizada em um processo industrial. Com isso, é preciso perceber que a expansão do mercado de reciclagem depende de uma série de preços e estes devem ser considerados. Ou seja, o custo da matéria-prima reciclável, considerando custos de coleta, separação, beneficiamento e transporte, deve ser cotejado com o custo da matéria-prima virgem, composto pelo custo de extração, da escassez de suas reservas e o custo de energia do seu processamento. A isso, devem ser somados os benefícios em termos de qualidade ambiental e de bem-estar da população associados ao reuso de materiais.

A questão energética, por sinal, é um elemento crítico nesse debate. Isto porque o crescimento econômico e os elevados padrões de vida são processos complexos que compartilham da necessidade de um abastecimento adequado e confiável de energia, que pode se originar do meio ambiente.

Hinrichs e Kleinbach (2003, p. 3) tratam da complexa relação entre energia e a sustentabilidade socioeconômica e ambiental:

$\mathrm{O}$ uso adequado da energia requer que se leve em consideração tanto as questões sociais como as tecnológicas. De fato, o crescimento econômico sustentável neste século (...) apenas pode ser possível com o uso planejado e eficiente dos limitados recursos energéticos e o desenvolvimento de novas tecnologias de energia.

As fontes de energia e os processos de desenvolvimento atuais ainda são, em grande parte, não renováveis. Dados da EIA (2014), responsável pelas estatísticas americanas oficiais relativas à energia, indicavam que em 2012 e 2013, menos de 10\% do consumo global de energia teriam origem em fontes renováveis, principalmente energia hidroelétrica e nuclear (aproximadamente 
90\% das fontes renováveis). O crescimento do consumo de energia foi sustentado praticamente pelo petróleo e o gás natural, que compuseram aproximadamente $60 \%$ da energia primária consumida entre 1980 e 2005. Contudo, há pequena mudança na participação relativa dessas duas fontes.

Enquanto o petróleo reduziu sua participação de 40\% em 1985 para 36\% em 2005, o gás natural aumentou de 20 para 24\% nesse período. As fontes renováveis são aquelas que não podem ser esgotados, como a hídrica, eólica, a solar e a biomassa.

No Brasil, a fonte renovável (hidráulica, cana de açúcar e outros) é um pouco mais representativa, mas ainda é menor que a não renovável (petróleo e derivados, carvão, urânio, lenha e gás). Enquanto na década de 1970 a fonte renovável era muito superior, principalmente pelo uso da lenha (64\% da produção de energia primária), em 2005 representava 47,3\%. O petróleo, contudo, aumentou de $16 \%$ da produção de energia primária em 1970 para 42\% em 2005. Isso mostra uma mudança na matriz energética, intensificando a dependência de combustível fóssil, que tem maior impacto ao meio ambiente.

Chaves (2012) lembra que dados do Ministério de Minas e Energia indicam que enquanto o consumo de energia cresceu a $3,7 \%$ ao ano entre 1970 e 2000, as emissões de CO2 associadas ao uso de fontes energéticas cresceram 3,3\% ao ano. Isso aumentou a importância pela busca de novas fontes energéticas, reaproveitando os recursos disponíveis. Trabalhar apenas com inovações na demanda por energia não seria suficiente para criar mecanismo de sustentação de um processo de desenvolvimento. Nesse aspecto, a busca pelo desenvolvimento de novas fontes renováveis abre espaço para novas experiências e inovações que demandam uma avaliação econômica, social e ambiental. Uma dessas fontes é a biomassa, alternativa de solução de dois problemas urbanos atuais: energia e resíduos sólidos. A energia de biomassa é derivada de matéria viva, como os grãos, as árvores e as plantas aquáticas.

Apesar de pouco representativo, o uso dos resíduos sólidos municipais incrementou-se significativamente na década de 1990 devido a um incentivo legal para produção de energia a partir dessa fonte nos Estados Unidos. Em 1960, quase 94\% do resíduo sólido eram descartados, seja para incineração ou para outra alocação, como aterros.

Esse cenário mudou a partir da década de 1990, quando a reciclagem, bem como a produção de energia, passaram a ter 
importância na disposição dos resíduos sólidos municipais americanos. Do total dos resíduos, em torno de $15 \%$ era utilizado para produção de energia e 15\% era reciclado. Em 2005, 34\% dos resíduos era material recuperado (reciclados e orgânicos que retornavam como adubos e fertilizantes) e $14 \%$ continuavam gerando energia. Ou seja, em torno de $48 \%$ dos resíduos sólidos municipais americanos eram reaproveitados como novos recursos (energia ou insumo) (EIA, 2014).

Para uma idéia do potencial da gestão de resíduos sólidos, IPEA (2010) estimou em mais de R \$ 8 bilhões os benefícios que poderiam ser gerados para a sociedade brasileira caso todo o resíduo reciclável encaminhado para aterros e lixões fosse efetivamente reciclado. Aí são incluídos os benefícios associados ao processo produtivo (insumos a partir de matérias-primas virgens ou material secundário) e os benefícios ambientais, englobando tanto energia quanto água consumida nos processos. Neste último, são incluídos a perde de recursos madeireiros, danos ao ciclo hidrológico, perda de biodiversidade, perda de potencial de descoberta de novas drogas para uso na saúde, impactos sobre a saúde ocupacional, danos por emissão de gases de efeito estufa, dentre outros. Em estudo realizado para o Rio Grande do Sul, Chaves e Souza (2013) estimam os benefícios econômicos em R $\$$ $4.456,00 / \mathrm{t}$ e os benefícios ambientais em $\mathrm{R} \$ 504 / \mathrm{t}$ no Estado.

É importante lembrar que esses vários aspectos associados à adequada gestão de resíduos, nem sempre são identificados de imediato. Ou seja, a aparente inviabilidade da coleta seletiva baseada nos custos de coleta perde validade quando as múltiplas dimensões da gestão de resíduos são consideradas. Além das vantagens econômicas e ambientais, outros benefícios sociais decorrentes da geração de trabalho e renda podem ser associados à reciclagem, conforme destacado anteriormente.

\section{Considerações finais}

Talvez o aspecto mais marcante do atual cenário da gestão de resíduos sólidos no Brasil seja aquele relacionado à destinação final dos resíduos. Os últimos dados disponíveis do IBGE, no final da década passada, indicam que a metade deles é destinada aos vazadouros a céu aberto, os chamados "lixões". Ao mesmo tempo, sabe-se que a Política Nacional de Resíduos Sólidos estabelece que até o ano de 2014, todos os municípios brasileiros deveriam 
possuir destinação final ambientalmente adequada dos rejeitos, o que não foi cumprido.

Além desse cenário pouco animador, também vale destacar que menos de $1 / 5$ dos municípios brasileiros possuem sistema de coleta seletiva, o que evidencia o potencial de reaproveitamento dos resíduos. A despeito das vantagens potenciais decorrentes da gestão adequada dos resíduos sólidos (com destaque para geração de trabalho e renda, economia de energia e água e benefícios á saúde e ao bem-estar da população), os custos comparativamente elevados em relação à coleta normal é um fator de desestímulo. Os dados mostram que a coleta seletiva apresenta um custo quatro vezes maior, induzindo à crença de que esta seria inviável economicamente.

É nesse contexto que o estudo dos benefícios sociais, econômicos e ambientais da gestão de resíduos e da reciclagem ganham importância. Estudos mostram que o mercado com potencial desperdiçado no Brasil alcança os $\mathrm{R} \$ 8$ bilhões. Se agregarmos a esse valor os ganhos relacionados aos aspectos ambientais e sociais, fica evidente que a "inviabilidade" do sistema é altamente questionável.

Considerando que o atual padrão produtivo e de consumo é altamente gerador de resíduos, a gestão adequada dos rejeitos é fundamental para minimizar os impactos de curto prazo decorrentes desse modelo. A isto, é fundamental associar políticas de estímulo às mudanças de fundo, sejam relacionadas aos processos produtivos, sejam relacionadas ao consumo consciente.

Entende-se que a Política Nacional de Resíduos Sólidos representa um avanço importante para a regulação do setor no país. Ainda que o seu horizonte de implantação seja de longo prazo, ela deverá representar uma mudança de paradigma. Ela envolve mudanças profundas nas práticas vigentes na sociedade brasileira, passando a primar pela redução e reaproveitamento de resíduos, por negócios inclusivos e pela responsabilidade compartilhada no que tange à produção/gestão de resíduos. O desafio, contudo, é torná-la efetiva.

\section{Referências}

ABNT - Associação Brasileira de Normas Técnicas. Normas Técnicas Brasileiras: NBR. 1.004- ABNT, 1993.

ASSOCIAÇÃO BRASILEIRA DE EMPRESAS DE LIMPEZA 
PÚBLICA E RESÍDUOS ESPECIAIS (ABRELPE). Panorama dos

Resíduos Sólidos no Brasil 2008. São Paulo, 2008.

BARTHOLOMEU, Daniela et al. Logística ambiental de resíduos sólidos. São Paulo: Atlas, 2011.

BRASIL. Lei n. 12.305 de 2 de Agosto de 2010. Disponível em: http:// www.mma.gov.br/post/conama.cfm?codlegi=6367. Acesso em: 12 set. 2011.

- Ministério das Cidades (Mcidades). SNIS Serie Histórica

7. Brasília: Secretaria Nacional de Informações sobre Saneamento/ MCidades, 2010.

CALDERONI, SEBATAI. Os Bilhões Perdidos no Lixo. São Paulo: Editora Humanitas/ FFLCH/USP, 2003.

CHAVES, Iara Regina; SOUZA, Osmar Tomaz. A gestão dos resíduos sólidos no Rio Grande do Sul: uma estimação dos benefícios econômicos, sociais e ambientais. Ensaios FEE. Porto Alegre: FEE, Vol. 34. Número Especial, p. 683-714, 2013.

CHAVES, Iara Regina. Benefícios sociais, econômicos e ambientais a partir da gestão de resíduos sólidos urbanos: uma estimação para o Rio Grande do Sul. Dissertação (Mestrado) - Programa de Pós-Graduação em Economia PUCRS, Porto Alegre, 2012.

CEMPRE. Pesquisa Ciclosoft 2008. Disponível em: http://www. cempre.org.br/ciclosoft_2008.php. Acesso em: 11 nov. 2012.

Pesquisa Ciclosoft 2010. Disponível em: http://www. cempre.org.br/ciclosoft_2010.php. Acesso em: 23 abr. 2014.

CONAMA, Resolução no 5 . 5 de agosto de 1993. Brasília-DF. Disponível em: http:/www.mma.gov.br/port/conama/res/res93/ res0593.html. Acesso em: 19 abr. 2014.

CRESPO, S. Educar para a Sustentabilidade: a educação ambiental no Programa da Agenda 21. In: Tendências na Educação Ambiental Brasileira. EDUNISC, 221-5, 2003.

EIA - Energy Information Administration. Total energy - recent data. Disponível em: http://www.eia.gov/totalenergy/. Acesso em: 19 abr. 2014.

HINRICHS, Roger A. KLEINBACH, Merlin. Energia e meio ambiente. São Paulo: Pioneira Thomson Learning, 2003. 
IBGE. Pesquisa Nacional de Saneamento Básico (PNSB). Instituto Brasileiro de Geografia e Estatística. Rio de Janeiro: IBGE, 2008.

Pesquisa Nacional de Saneamento Básico (PNSB). Rio de Janeiro: IBGE, 2010.

IPEA. Pesquisa sobre pagamento por serviços ambientais urbanos para gestão de resíduos sólidos. Instituto de Pesquisa Econômica Aplicada. Brasília: IPEA, 2010.

MOTTA, Ronaldo Seroa da. Economia ambiental. Rio de Janeiro: Editora FGV, 2006.

MOTTA, Ronaldo Seroa da; CHERMONT, Larissa Steiner. Aspectos econômicos da gestão integrada de resíduos. Rio de Janeiro: IPEA/ DIPES, Maio de 1996.

STRAUCH, Manuel. Gestão de recursos naturais e resíduos. In: STRAUCH, Manuel; ALBUQUERQUE, Paulo Peixo de (Orgs.). Resíduos: como lidar com os recursos naturais. São Leopoldo: Oikos, 2008, p. 29-84.

UNCED. Agenda 21 - United Nation Conference on Environmental and Development, 3-14 june. Rio de Janeiro, 1992.

\title{
RECYCLING AND SOLID WASTE MANAGEMENT AS OPPORTUNITIES FOR THE GENERATION OF SOCIAL BENEFITS , ECONOMIC AND ENVIRONMENTAL
}

\begin{abstract}
In this paper we present some discussions related to the production and management of solid waste in Brazil. Particularly, we discuss the potential for generating social, economic and environmental benefits of waste management based on National Solid Waste Policy, created by federal law in 2010. This is the policy that defines goals and objectives for waste management in the country. Among their objectives, it is said that by the year 2014 all municipalities should provide a correct management for the waste produced to eliminate most of environmental damage from the open dumps. This is because the recent scenario shows around $50 \%$ of the solid waste produced are destined for the open dumps, called "lixões". This is both a waste of an economic perspective, as social and environmental given the potential benefits they present for reuse and recycling.
\end{abstract}

Keywords: Recycling, National Solid Waste Policy, Socioeconomic and Environmental Benefits. 